\section{Pós-colonialismo versus pós-autoritarismo: o mundo árabe e a América Latina em uma perspectiva comparativa*}

Recebido: 18.04 .18

Aprovado: 30.05 .18

\begin{abstract}
Sari Hanafi**
Resumo: Neste artigo, o autor desafia uma corrente tendência de culpabilização dos intelectuais árabes por não acompanharem os levantes populares árabes, orientando seus públicos e movimentos sociais. Em direção contrária, o autor apresenta o intenso debate ocorrido sobre o tema na academia e nas mídias de massa, indicando que o que houve foi na verdade o fracasso das escolas de pensamento de acadêmicos da esquerda pós-colonial e anti-imperialista. Apresenta, em consequência, como a interseção entre as ciências sociais e os estudos pós-coloniais não se dá sem problemas, principalmente quando se tenta projetar tais estudos sobre o contexto árabe. Sugere então que a abordagem pós-colonial deveria ser complementada por uma abordagem pós-autoritária, que poderia servir tanto ao mundo árabe quanto à América Latina.
\end{abstract}

Palavras-chave: Pós-colonialismo. Pós-autoritarismo, mundo árabe. América latina. Ocidente/ Oriente.

\section{Post-colonialism vs. post-authoritarianism: the Arab world and Latin America in a comparative perspective}

Abstract: In this article, the author challenges a current trend of blaming Arab intellectuals for the failure to accompany the Arab uprisings and guide their publics and their social movements. The author challenges this tendency and argues that there has been intense debate on the subject in academia and the mass media, and indicates that what occurred was, in fact, the failure of the schools of thought of post-colonial and anti-imperialist leftist scholars. He consequently shows how the intersection between the social sciences and post-colonial studies is not without friction, especially when trying to project such studies on the Arab context. He suggests that the post-colonial trend should be complemented by a post-authoritarian approach, which could serve both the Arab and Latin American worlds.

Keywords: Postcolonialism. Post-authoritarianism, Arab world. Latin America. West/East.

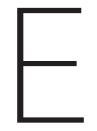

xiste uma tendência na mídia e nos trabalhos acadêmicos árabes de culpabilização dos intelectuais árabes por não acompanharem os levantes populares na África do Norte e no Oriente Médio, e orientarem seus povos e movimentos sociais. Neste artigo, eu desafio essa tendência, argumentando que existiram imensos debates levantados a partir da produção acadêmica de conhecimento e mesmo pela grande mídia, especialmente os jornais e a TV. Para mim, a questão, na realidade, foi o fracasso de certas escolas de pensamento de acadêmicos e

\author{
* Tradução: Diogo \\ Saraiva e Solange \\ Miguel Marcondes \\ Armando. \\ ** Sari Hanafi \\ é professor de \\ sociologia e \\ presidente do \\ Departamento \\ de Sociologia, \\ Antropologia e \\ Estudos de Mídia da \\ American University \\ of Beirut, Beirute, \\ Líbano. <sh41@aub. \\ edu.lb>.
}


intelectuais públicos que pertencem ao que chamarei de esquerda pós-colonial e anti-imperialista.

Ao focar nos trabalhos acadêmicos, argumentarei que a interseção entre as ciências sociais e os estudos pós-coloniais não se dá sem problemas, refletindo uma crise da esquerda árabe que adota o pós-colonialismo como perspectiva exclusiva, e o distorce ao projetá-lo sobre o contexto árabe. Salientarei duas características da esquerda árabe, nomeadamente posturas excessivamente anti-imperialistas e antiocidentais. Irei até mesmo sugerir que a abordagem pós-colonial deveria ser complementada por uma abordagem pós-autoritária. Apesar desse artigo focar nos debates do mundo árabe, ele também levará a algumas comparações com a América Latina.

Atualmente, pode-se testemunhar uma ampla e acalorada discussão pelo mundo. Talvez o momento mais (verbalmente) violento dessa discussão esteja no debate entre Slavoj Žižek, Walter Mignolo e Hamid Dabashi. Esse último declara, em seu Non-Europeans can think, sua independência, não apenas da condição da pós-colonialidade, mas das epistemes limitadas - e hoje exauridas - historicamente ocasionadas por ela. Ele lamenta o fato de duvidar que "filósofos europeus possam ler algo [escrito por não-europeus] e, de fato, aprender a partir disso - em vez de assimilá-lo ao que já conheciam" (Dabashi, 2017).

\section{Debate pós-colonial}

O pós-colonialismo é uma teoria e prática que, desde seu surgimento nos anos 1960 com Edward Said, Homi Bhambra e Gayatri Spivak, tem sido recortada por debates e controvérsia. Uma das maiores críticas se dá sobre a forma em que essa tendência gera categorias binárias (tradição/modernidade, Ocidente/Oriente, racional/irracional, língua inglesa/língua vernacular etc.). Para outros - como Sadeq Jalal al-Azem e Mahdi Amel, ambos do mundo árabe -, essa teoria sobrevaloriza o cultural à custa do econômico. Como argumentam Geoffrey Nash, Kathleen Kerr-Koch e Sarah Hackett,

no entanto, a tradição do pensamento pós-colonial, seguindo seus principais pensadores, busca teorizar o epistemológico, o psicológico e o ideológico no interior da dominação ocidental, assim resgatando e recuperando uma versão da autonomia ao invés de sobrepujar as estruturas do capitalismo global (Nash, Kerr-Koch \& Hackett, 2013). 
Essas duas orientações teóricas e agendas políticas tão diferentes tornaram-se fonte de conflitos e discórdia em debates mundiais, até mesmo no mundo árabe e na América Latina.

Na América Latina, o debate ganhou importância com uma teorização diferente. Aníbal Quijano (sociólogo peruano), Walter Mignolo (sociólogo argentino) e Enrique Dussel (filósofo argentino) foram os primeiros a teorizar o conceito de colonialidade, seguidos por Edgardo Lander (sociólogo venezuelano). Eles vêm trabalhando uma perspectiva da modernidade/colonialidade que postula a experiência da modernidade com significados radicalmente diferentes no Norte e no Sul.

Para Aníbal Quijano, o processo de independência política sem uma revolução social está por trás dos padrões básicos atuais da colonialidade do poder. No mesmo espírito, Mignolo argumenta que o mundo de hoje é caracterizado por uma "matriz colonial de controle" que foi estabelecida com a modernidade e continua até o presente. A colonialidade seria, portanto, uma parte inerente da modernidade, entendida como era histórica. Mignolo explicita os três níveis da lógica da colonialidade: a colonialidade do poder, das estruturas políticas e/ou econômicas; a colonialidade do saber, que se refere à epistemologia, filosofia, ciência e linguagem; e a colonialidade do ser, que se refere à subjetividade, tal como percepções sobre papéis de gênero e a sexualidade.

Em sua filosofia da libertação, Dussel não apenas critica o eurocentrismo como fornece uma ampla teoria que abrange a dominação nos campos do gênero/sexualidade, pedagogia, religião e economia (Kohn \& McBride, 2011: 131). Ele delineia uma articulação de dois conceitos: a totalidade totalizante como a assimilação violenta de tudo que é alheio. Dussel foca na conquista europeia das Américas como o momento definidor da modernidade, deixando claro que o colonialismo ocidental é a ilustração paradigmática da lógica da totalidade. A externalidade é o segundo conceito, que trata do "o âmbito em que outras pessoas, livres e não condicionadas pelos sistemas do observador, não participando de seu mundo, se revelam." Para ele, a América Latina está na posição de externalidade em relação aos centros de poder econômico e cultural americanos/europeus; e os pobres do Terceiro Mundo estão em posição para desafiar a visão de que o capitalismo, o colonialismo e a globalização sejam benéficos para todos os participantes nessas relações hierárquicas (Kohn \& McBride, 2011: 132). Ele concede privilégio epistêmico aos oprimidos. Wendy Brown (2001) sugere que as políticas identitárias moralizadas podem ser uma forma de ressentimento que instrumentaliza a impotência da expropriação, no esforço de assumir uma superioridade moral. 
Já Edgardo Lander - em seu livro editado em 1993 com outros colaboradores - teve um papel instrumental não somente na crítica do eurocentrismo e do orientalismo, mas também no papel das ciências sociais em relação às mulheres, à natureza, ao poder e à economia.

Apesar desses quatro autores terem produzido discernimentos incríveis sobre a necessidade de informar nossas análises atuais com o impacto dos processos coloniais históricos, qualquer tentativa de considerar suas abordagens de forma exclusiva irá falhar ao explicar as dinâmicas atuais. Por exemplo, se constatarmos, a partir de Edgardo Lander (2013), que muitas ONGs venezuelanas são financiadas pelos Estados Unidos, quanto dessa "gramática política colonial/eurocêntrica" vai nos informar sobre as dinâmicas sociais e políticas da Venezuela de hoje, em relação, por exemplo, à crise interna real do regime venezuelano atual.

Mais recentemente, considerei o volume Coloniality at large: Latin America and the postcolonial debate (Morana, Dussel \& Jaregui, 2008) extremamente interessante em suas investigações sobre as raízes regionais do pensamento crítico na América Latina, oferecendo críticas agudas à aplicabilidade da teoria colonial no continente, com artigos das áreas de sociologia, crítica literária, filosofia e história. Conceitos preciosos ao pensamento pós-colonial, como a colonialidade, a diferença colonial, o ocidentalismo e a dependência são definidos e analisados em relação à modernidade, à pós-modernidade e à globalização. Quase todos os colaboradores deixam de trazer o debate colonial ao presente, e muito menos ao futuro. Uma das exceções é a discussão do secularismo como categoria eurocêntrica que considerei muito relevante em relação à discussão atual sobre religião e religiosidade. As principais contribuições à teoria pós-colonial foram feitas nos anos 1980 e 1990 e poucas diziam respeito à América Latina. De qualquer forma, existem sérias limitações na capacidade da teoria pós-colonial informar e refletir os movimentos populares do mundo globalizado de hoje.

Nesse artigo, apresentarei um tipo diferente de crítica às metamorfoses pós-coIoniais, avaliando a produção de acadêmicos e produtores de conhecimento pós-coloniais que exageram o papel do imperialismo e geram uma relação binária de oposição ao Ocidente. 


\section{Acadêmicos anti-imperialistas \\ e teóricos da conspiração}

Apesar de concordar com Prabhat Patnaik (2011) quando afirma que o imperialismo não se tornou um conceito obsoleto e que detém algum significado na vida atual, entendo que sua realidade se transformou, não podendo ser entendida como uma simples dominação política e econômica do poder imperial sobre o resto do mundo. Em outras palavras, o imperialismo perdeu sua hegemonia. A importância do papel do Estado (Harvey, 2005) ou o notável papel da cultura e das corporações transnacionais podem ser melhor capturadas pela noção de império (Hardt \& Negri, 2001) do que a de imperialismo. Em uma análise cuidadosa da relevância do conceito de imperialismo para entender a crise do mundo árabe pós-levantes populares, os poderes mais influentes não são somente os poderes imperiais clássicos, mas também o Irã, as monarquias do golfo, a Turquia. Todos buscam tornar-se impérios.

Depois de meio século de autoritarismo no mundo árabe, os acadêmicos pós-coloniais anti-imperialistas não conseguiram compreender as dinâmicas locais de poder, ou as tem ignorado. Para eles, a democracia não ocupa o topo de sua agenda. Pior: alguns não incluem a democracia em suas agendas. Por isso David Scott (2004) testemunhou o fim do projeto Bandung e a transformação de utopias anti-coloniais em pesadelos pós-coloniais.

Esses acadêmicos entenderam os levantes árabes (com todas as suas ramificações: mudanças políticas, violência e discórdia civil) como um simples jogo geopolítico em que os antigos mestres coloniais e imperiais estão onipresentes e são os únicos responsáveis pela situação. Esse é um pensamento conspiratório na definição de Jeffrey Kluger: "você não quer se culpar por suas falhas e lacunas, então, ao invés disso, você culpa forças anônimas" (Kluger, 2017). De fato, as teorias da conspiração são para perdedores, literalmente, não pejorativamente. As pessoas que perderam uma eleição, dinheiro ou influência vão buscar uma explicação para essa perda (Uscinski \& Parent, 2014).

Retratar dessa forma a transformação atual das sociedades árabes faz com que muitos desses acadêmicos simplesmente defendam ditadores árabes "progressistas". Essa apologética quase conspiratória, em conjunção com uma análise defensiva, torna-se ferramenta para justificar a repressão local e mesmo a tortura. Os acadêmicos pós-coloniais da região árabe, bem como alguns esquerdistas do Ocidente, raramente articularam um grupo de influências internas e externas que moldaram o panorama político do mundo árabe. No mesmo sentido, Achille Mbembe critica 
o marxismo por se apresentar como "radical e progressista", quando, de fato, ele desenvolve um

imaginário da cultura e política em que a manipulação da retórica de autonomia, resistência e emancipação tem o papel de único critério capaz de determinar a legitimidade para o discurso Africano autêntico [de forma a virar, em sua raiz], um culto da vitimologia (Mbembe, 2000: 5 apud Hoffmann, 2017).

The Arab Spring: the end of postcolonialism, de Hamid Dabashi (2012), é a melhor crítica do regime de produção de conhecimento que ignora o desenvolvimento e as transformações sociais e intelectuais no mundo árabe. De forma mais geral, as críticas pós-coloniais têm ignorado as crises atuais na África, no Timor Leste, Myanmar, Peru e outras sociedades sofrendo com as estruturas neocoloniais (San Juan, 1998), mas também de estruturas que não derivam em nada da condição da colonialidade. As tentativas pós-coloniais de reificar a diferença cultural e gerar uma compaixão cultural lidou de forma falha com a realidade da globalização, tanto em seus aspectos históricos e em sua recente intensificação, como com as contradições históricas específicas da crise contínua do capitalismo tardio e transnacional e dos regimes opressores de muitos países do Sul.

Para ilustrar esse argumento, tomarei um exemplo da obra de Gurminder Bhambra. A despeito de ser louvável seu excelente trabalho acadêmico sobre a forma em que, segundo os entendimentos sociológicos da modernidade, as experiências e reinvindicações de "outros" não europeus têm sido invisibilizada nas narrativas dominantes e no arcabouço (Bhambra, 2014), a sua abordagem pode ser reducionista na análise de certos fenômenos sociais. Em suas palestras intituladas "Postcolonial reconstructions of Europe", apresentadas na IX Conferência da Associação Sociológica Europeia (Praga, 2015), ela retrata os refugiados sírios na Europa meramente como migrantes pós-coloniais. Ela explica que a Europa, lar dos antigos mestres coloniais, os atrai e que as sociedades brancas europeias não os quer porque essas sociedades não lidaram com a memória de seus legados coloniais. Essa abordagem pós-colonial não leva em conta o fato de que essa onda de exilados foi gerada por uma violenta virada autoritária no mundo árabe, em que o peso de regimes locais autoritários (por exemplo, no caso da Síria, o regime de Assad, a Arábia Saudita, o Qatar e o Irã são atores importantes) é maior do que o dos poderes ocidentais imperiais. 


\section{Acadêmicos antiocidentais}

A segunda característica dos acadêmicos pós-coloniais esquerdistas é seu antiocidentalismo. Eles entendem o pós-colonialismo como uma abordagem que serve para "desocidentalizar" a produção de conhecimento na região árabe. No entanto, ao contrário do orientalismo de Edward Said (1978), Talal Asad não enfatizou as origens ocidentais dos conceitos sociais em si, mas a autoridade por trás desses discursos (Bardawil, 2016). Alguns daqueles que clamam por conhecimento desocidentalizado acabaram por se empobrecer em virtude de uma tendência em louvar os feitos de acadêmicos históricos locais. Patrick Williams (apud Said, 1978) defende a importância do orientalismo, argumentando que, independentemente da utilização desse em teorizações anti-humanistas, nele o Ocidente não é retratado simplesmente como um "outro". No entanto, a forma pela qual esse influente livro foi entendido e citado no mundo árabe reproduziu o binarismo Oriente/Ocidente. Alguns autores árabes resistiram a essas tendências, como Abdullah Laroui:

A negação da cultura ocidental não constitui, em si só, uma cultura, e o vagar delirante em torno de uma identidade perdida nunca vai trazê-la de volta do pó (Laroui, 1967).

Como editor do Arab Journal of Sociology (Idafat) desde 2006, muitas vezes encontrei usos decorativos de referências a Ibn Khaldoun (1332-1406) ou Malik Bennabi (1905-1973), ou ainda análises forçadas para encaixar algum de seus conceitos em um texto. Por exemplo, apesar do fato de que a autoridade francesa colonial e o governo pós-independência terem destruído a estrutura tribal na Argélia, muitos pesquisadores sociais continuam a utilizar a asabiyya (coesão tribal) como elemento importante das organizações políticas. Esses usos e abusos também podem ser encontrados naqueles que defendem a islamização do conhecimento como um todo e das ciências sociais em específico (Hanafi, 2016). Eles conceituam uma antítese da ciência social "ocidental" por meio de uma estrutura de antinomias à modernidade, ao desenvolvimento, à democracia e ao secularismo. Essa abordagem foi fundada com base em uma relação pressuposta com o Ocidente. Ao identificar uma tradição "ocidental" singular e monolítica, a trajetória da islamização ignora a diversidade "interparadigmática", a exemplo das diferenças axiomáticas entre a escola marxista, cujas unidades de análise são primariamente baseadas em classes, e as abordagens funcionalistas, que marginalizam essas unidades de análise baseadas em classe. Uma breve observação dos diversos paradigmas dentro da sociologia dita "ocidental" demonstra que essas trajetórias em disputa não podem ser reduzidas tão somente a uma escola. A mesma observação se aplica às ciências sociais islâmicas; a diversidade do campo previne contra as generalizações de todo tipo. 
A produção civilizacional de fronteiras (Oriente/Ocidente; tradição/modernidade etc.) não foi um mecanismo heurístico para compreender as mudanças do mundo árabe. Dito isto, sou favorável ao uso de fontes locais de conhecimento, não apenas em termos de dados, mas também de conceitos e teorias, e isso deve ser conduzido não como um projeto nacionalista, mas como uma necessidade para lidar com realidades locais. O trabalho recente de Syed Farid Alatas e Vineeta Sinha (2017) é extremamente interessante ao propor uma sociologia alternativa que se relaciona com diferentes tradições sociológicas, incluindo as teorias ocidentais, mas indo além do eurocentrismo e androcentrismo. Em outras palavras, pode-se gerar discussões entre, por exemplo, Ibn Khaldoun e Michel Foucault ao discutir transformações do regime político na Arábia Saudita, ao invés de ter de escolher apenas um dos dois.

Os argumentos pós-coloniais subitamente unificaram uma parcela da esquerda com uma parcela do islamismo político em sua contínua culpabilização do Ocidente por qualquer problema social, econômico e político da região.

\section{Rumo a uma abordagem pós-autoritária}

O que proponho aqui é a complementação dos estudos pós-coloniais com o que chamo de estudos pós-autoritários. O parentesco léxico com o pós-colonialismo significa que essa abordagem poderia, por associação, beber de um número de pressupostos que sustentam aquela categoria, especialmente em relação às estruturas de poder, mas não no sentido de que tenhamos, ao final, entrado em acordo com o autoritarismo ou que agora estejamos "post" essa era.

Esse campo deve, primeiramente, dar atenção às diferentes maneiras em que os regimes autoritários moldam a produção de conhecimento e, em segundo lugar, como os acadêmicos manobram e resistem abertamente a esses regimes. Isso significa que devemos conduzir críticas duplas, seguindo a proposta de Abdelkaber Khatibi:

\footnotetext{
A tarefa essencial da sociologia árabe é realizar trabalho crítico dentro de duas correntes:

i. a desconstrução de conceitos que emergiram do conhecimento e discurso sociológico daqueles que falaram em nome da região árabe, marcados por uma ideologia ocidental e etnocêntrica; e

ii. a crítica simultânea do conhecimento e discurso sociológico sobre as várias sociedades árabes produzidos pelos próprios árabes (Khatibi, 1983: 34).
}

Por que precisamos de estudos pós-autoritários? Muitas são as razões. Vejamos as principais: 
Primeiramente, há uma escassez de estudos sistemáticos, no sentido adiantado por André Béteille (2013), ou seja, o estabelecimento de interconexões entre os processos sociais de maneira sistemática, sem nenhuma pressuposição sobre serem estas interligações basicamente harmoniosas ou discordantes. Muitas das pesquisas sociais no mundo árabe se contentam em entender/descrever de forma simples um fenômeno social sem o conectar com a economia política e a natureza das escolhas políticas adotadas pelo Estado. Uma consulta a dois periódicos de ciências sociais do Golfo Árabe ilustra que as ciências sociais estão desprovidas dessa dimensão. A sociologia vira o estudo de microproblemas com técnicas científicas, sem tratar da natureza autoritária das monarquias da região e outras estruturas de poder. De fato, existe uma tendência de empirismo desconectado de discussões sobre política econômica ou dos imperativos morais da justiça e respeito à Declaração Universal de Direitos Humanos. Nesse sentido como Ghassan Hage acertadamente apontou -, muitos pedidos por rigor empírico científico são seletivos em face de evidências esmagadoras, tornando-se uma técnica de negação, como no caso da negação de responsabilidade ao regime sírio por assassinatos em massa, bombardeios e o uso de armas químicas. Essa técnica também é observada entre aquele que negaram o holocausto, nomeadamente pela ausência de evidências conclusivas sobre as câmaras de gás ou sobre o número preciso de vítimas.

Em segundo lugar, a autocensura dos acadêmicos satura a produção de ciências sociais de questões implícitas. Por exemplo, muitas vezes encontramos críticas amplas à sociedade ou ao Estado, e a mensagem fica diluída. Aqueles que resistem devem adiantar uma abordagem muito sutil, ou podem acabar na prisão. O medo não é apenas do Estado, mas também de alguns grupos ideológicos radicais, como islamistas radicais e fascistas secularistas/militaristas. Torna-se importante o papel de intelectuais imigrantes e exilados, que, muitas vezes, gozam de liberdades mais amplas do que em países árabes, de proteção do papel crítico da intelectualidade, como sugerido por Edward Said (1978).

Em terceiro lugar, os Estados autoritários muitas vezes conferem primazia à causa "nacional" em relação às causas sociais. Com isso, os fatores externos são muitas vezes exagerados em relação aos locais. A forma em que os levantes árabes foram analisados demonstra essa tendência. A consulta de alguns escritos da esquerda árabe em 
meios acadêmicos (Hanafi \& Arvanitis, 2016, Capítulo 8) e em colunas editoriais de jornais libaneses (Hanafi \& Arvanitis, 2016, Capítulo 9) demonstra a falta de discussões sociológicas sobre a causa de as pessoas se revoltarem, ou sobre o uso sistemático de tortura na Síria ao longo do último meio século, gerando situações sociais e políticas que não podem ser ignoradas simplesmente porque o regime sírio fornece armas ao Hezbollah, contribuindo para a resistência contra Israel.

Em quarto lugar, os regimes árabes autoritários têm encorajado uma monocultura alinhada com a narrativa oficial, relegando outras narrativas a esferas privadas e semiprivadas. A ausência de uma esfera pública habermasiana, necessária para a interação e o crescimento mútuo intelectual, tem contribuído para o aprofundamento da fissura entre a esquerda liberal e os grandes segmentos de islamistas. A responsabilidade aqui não é apenas do Estado ou de um desses lados, mas de todos os envolvidos em diferentes graus. Não é exagero dizer que testemunhamos conflitos que são quase guerras civis, como no caso do Egito ou da Líbia. Os estudos pós-coloniais falharam em sua compreensão do "outro" (o islã popular, o islã político), que se torna também interno, e não somente externo (Ocidente). O trabalho de Christina Phillips (2013) sobre a literatura árabe moderna claramente demonstra que a concentração da teoria pós-colonial no binarismo colonizador/colonizado é limitante em relação a tópicos como identidade e nação árabe. Ela argumenta que a relação entre o eu e o outro como local de disputa de poder, de ambivalência e independência é equivalente à proposta de uma colonização interna substituta, pela qual os escritores seculares, se não diretamente vinculados à penetração colonial no Egito, de uma forma ou de outra apoiaram o discurso nacionalista de sua geração, afiliado ao Ocidente.

Em quinto lugar, o medo e a suspeita em relação a qualquer conceito universal tal como os direitos humanos. Parte da produção acadêmica produzida em regimes autoritários propaga a mitologia da singularidade de cada sociedade e de cada cultura.

Em sexto lugar, a hesitação para engajar com o público e os tomadores de decisão tem reduzido a produção de conhecimento a um conhecimento profissional (Hanafi \& Arvantis, 2016, Capítulo 5). Tendo em vista o fato de que o Estado autoritário não está interessado em construir uma política baseada em evidências, a produção de conhecimento se 
configura como pesquisas baseadas em projetos, em oposição a pesquisas baseadas em programas, utilizando financiamento que muitas vezes vêm do exterior.

Em sétimo lugar, a boa pesquisa crítica produzida sob o autoritarismo muitas vezes leva à marginalização da carreira de seus autores.

Em oitavo lugar, os estudos pós-autoritários são necessários porque as agências de financiamento não se encontram exclusivamente no Ocidente, mas também em países conhecidos por seu autoritarismo, como as monarquias do Golfo.

Os estudos pós-autoritários, então, deveriam lidar com todas as questões acima, se pretendemos gerar não apenas novas epistemologias, mas também condições de trabalho salubres que conduzam a boas práticas de pesquisa.

\section{Conclusão}

O pós-autoritarismo é um projeto político preocupado com a reconstrução e reorientação do conhecimento, da ética e das estruturas de poder locais. Ele não visa funcionar isoladamente como formação teórica singular, mas sim como amplo conjunto de perspectivas, conceitos e práticas que se desenvolvem em resistência ao autoritarismo. Não estou declarando a morte do pós-colonialismo e desejando longa vida aos estudos pós-autoritários, mas simplesmente apontando que não podemos entender a situação atual da produção de conhecimento somente por meio uma exploração do passado remoto, esquecendo como essa produção é também moldada pelas subjetividades políticas locais. Para entender as perturbações atuais do mundo árabe e suas ramificações sociais, políticas e econômicas, precisamos prestar menos atenção aos efeitos pós-coloniais e muito mais atenção aos efeitos dos regimes autoritários.

Pode-se perguntar se os estudos pós-autoritários devem estar focados apenas nos países obviamente autoritários, como alguns do mundo árabe. A resposta é: de forma alguma. Hannah Arendt (1985), no seu Origens do totalitarismo, insistiu no aprendizado para o reconhecimento de como diferentes elementos do fascismo, em diferentes períodos históricos, se cristalizavam em novas formas de autoritarismo. Esses elementos antidemocráticos se combinam de forma muitas vezes imprevisível, e acredito que podem ser encontrados em uma variedade de práticas e valores políticos que caracterizam muitos países do mundo, até mesmo no Ocidente. Como Henry A. Giroux bem disse, 
o discurso de liberdade e igualdade que emergiu com a modernidade parece ter perdido seu valor até mesmo residual como projeto central da democracia (Giroux, 2007).

Com a Guerra ao Terror, o fundamentalismo de mercado e a radicalização religiosa, muitos valores democráticos se erodiram, e o primeiro deles é a liberdade de expressão. Em implacável editorial da revista Global Dialog, Michael Burawoy resume habilmente:

Duterte (das Filipinas), Erdogan (da Turquia), Orban (da Hungria), Putin (da Rússia), Le Pen (da França), Modi (da Índia), Zuma (da África do Sul) e Trump (dos Estados Unidos) - todos eles parecem ser da mesma laia nacionalista, xenófoba e autoritária (Burawoy, 2017).

Para ele, o triunfo de Trump deu novas energias aos movimentos iliberais e às ditaduras, mas a reação política às democracias liberais vem se formando há décadas, na medida em que impulsionaram a terceira onda da mercantilização, com sua precariedade, exclusão e desigualdade.

A afirmação do antigo primeiro ministro francês Manuel Valls e de seu equivalente canadense Stephen Harper de que não há tempo para "cometer sociologia", ao tempo em que se referiam à necessidade de tomar atitudes duras contra os terroristas ao invés de estudar as causas do terrorismo, é uma forma de intervir no trabalho dos sociólogos de ambos os países. Nessa nova onda de autoritarismo, que paira sob o mundo árabe, mas também ao redor do globo, há um sério ataque à academia crítica. Precisamos refletir sobre as questões implícitas em nossa produção de conhecimento. A crítica social tem que ser pareada com uma autocrítica vibrante

* "[...] that sense of always looking at one's self through the eyes of others, of measuring one's soul by the tape of a world that looks on in amused contempt and pity. One ever feels his two-ness,an American, a Negro; two souls, two thoughts, two unreconciled strivings; two warring ideals in one dark body, whose dogged strength alone keeps it from being torn asunder" (n. dos t.). e a vontade de assumir posicionamentos críticos, isso sem se tornar dogmático ou intratável (Giroux, 2007).

Os estudos pós-autoritaristas se inspirariam no trabalho do sociólogo afro-americano W. E. B. Du Bois (2013). Em seu trabalho autoetnográfico The soul of black folk, ele forja a noção de dupla consciência:

Aquele sentido de sempre olhar-se a si mesmo através dos olhos dos outros, de medir a própria alma pela fita de um mundo que olha encantado de menosprezo e piedade. Sente-se a "doícia" um americano, um negro, duas almas, dois pensamentos, duas batalhas sem trégua, dois ideais em guerra em um corpo escuro, cuja força irredutivel - apenas ela - impede que seja despedaçado (Bois, 2013)*. 
Com essa dupla consciência, deve-se conduzir duplas críticas com a faculdade de analisar a complexidade da formação identitária no mundo árabe em sua relação com as dinâmicas locais, internacionais e transnacionais.

Recentemente, muitos eventos no mundo árabe comemoraram um século do Acordo Sykes-Picot e as intervenções coloniais e divisões geográficas da região árabe. Enquanto muitos dos que falaram argumentaram pelo contencioso efeito divisor que os poderes coloniais exerceram sobre a região, eu sugeri, além disso, a identificação de políticos locais que tenham fomentado as divisões, ao invés de políticos franceses, ingleses ou americanos, e eu pedi para que a plateia refletisse sobre o fato de que o Estado Islâmico removeu os postos de fronteira entre o Iraque e a Síria em 2014, como parte do plano proclamado pelo grupo de restaurar o Califado Islâmico sobre as ruínas da fronteira de Sykes-Picot, bem como outras fronteiras geográficas e sociais operadas por poderes regionais, que incluem a Arábia Saudita, o Irã, o Egito e a Síria.

Esse artigo propõe uma análise criteriosa das categorias binárias desenvolvidas no âmbito dos estudos pós-coloniais. A proliferação desses binarismos tem sido realizada a expensas de noções cruciais como classe, etnia, nação e gênero, tornando opacos os processos econômicos subjacentes à apropriação de terras na expansão dos territórios, à exploração de recursos, incluindo a força de trabalho humana, e a institucionalização do preconceito racial e por gênero. Eu tenho uma grande resistência contra o binarismo Ocidente/Oriente: é preciso muito cuidado para não pensar na circulação internacional de conhecimento a partir da noção de "importação e exportação", já que essa abordagem é ineficaz para analisar as trocas conceituais e intelectuais a partir da perspectiva da periferia. Nesse sentido, o livro da Fernanda Beigel (2011) The politics of academic autonomy in Latin America. Public intellectuals and the sociology of knowledge é bastante explícito contra a noção de centro-periferia. O uso dessa abordagem nos estudos sociais da ciência pode levar ao pressuposto que as economias dependentes andam de mãos dadas com um "Estado" de produção de conhecimento igualmente subordinado, o que, por sua vez, significa que se espera que as contribuições periféricas ao desenvolvimento científico internacional se tornem nulas. No fim, essas categorizações tendem a ter um efeito contraproducente na história da ciência, preservando imagens de uma ciência universal apoiada na violência simbólica.

O conceito centro-periferia primeiramente reforça a ideia de que há uma ciência dominante baseada nas tradições europeias e norte-americanas, que produzem "originalidade", retratando as periferias como espaços científicos pacíficos em que 
1. Além dessa base dados, existe outra, criada pela ProQuest, que não é de acesso livre: A Latin America \& Iberia Database, que inclui periódicos acadêmicos atuais publicados em diferentes países latino-americanos, Espanha e Portugal. necessariamente falta a "originalidade", tornadas meras consumidoras de conhecimento importado. O orçamento participativo criado na cidade de Porto Alegre é um modelo teorizado e promovido no Brasil. Hoje, é utilizado em muitas cidades ao redor do mundo, especialmente na América Latina, na Alemanha e nos Estados Unidos (Keel, 2016). A justiça de transição é uma disciplina desenvolvida na América Latina que fornece lições incríveis sobre como lidar com violações de direitos humanos em massa, perseguições, reparações, com as memórias das vítimas e comissões da verdade. Eu tenho uma afinidade pessoal com o trabalho de Sérgio Adorno sobre a violência, trabalho que descobri graças à biblioteca virtual de acesso livre do Conselho Latino Americano de Ciências Sociais (Clacso). ${ }^{1}$ Aqui podemos ver que a originalidade, e até mesmo a universalidade, precisam de uma ferramenta de visibilidade. A criação de uma variedade de bases de dado regionais e linguísticas viabilizam uma superação do eurocentrismo e dos efeitos da colonialidade. O Relatório da Comissão Gulbenkian é talvez a análise mais reveladora das mudanças profundas que vêm acontecendo no pensamento social na segunda metade do século XX (Wallerstein, 1997). Esse relatório demonstra as formas em que as estruturas eurocêntricas do conhecimento têm erodido, tanto nos países centrais como na periferia, e como as escolas de pensamento emergentes visam desenvolver formas alternativas de entendimento social e realidade histórica (Germana, 2014).

Sari Hanafi e Rigas Arvanitis (2016) reiteram as análises de Fernanda Beigle (2011) quando observam especificamente as práticas de pesquisa árabes e como a questão está menos relacionada à dependência estrutural de muitos acadêmicos árabes em relação a universidades de elite e mais a uma dependência optativa, ao negligenciarem a produção em sua própria língua. Em outras palavras, aqueles que decidem publicar globalmente perecem localmente. Ou, ao contrário, aqueles que publicam na língua materna decidem perecer globalmente.

Syed Farid Alatas e Vineeta Sinha (2017) argumentam que o eurocentrismo e o androcentrismo permanecem como preconceitos persistentes no ensino das ciências sociais, mas a solução está com o princípio da diversidade e não com a rejeição da teoria social ocidental. Sujata Patel argumenta:

\footnotetext{
A teoria social precisa afirmar o princípio das diversidades. Eu utilizo o conceito das "diversidades" porque ele evoca mais sentidos que outros conceitos que vêm sendo utilizados, como "alternativa", "múltipla" ou "cosmopolita". Em muitos idiomas utilizados em países ex-coloniais (incluindo as línguas coloniais, como o inglês), o termo diverso teve uso multivariado e seus sentidos vão desde uma simples afirmação da diferença até a elaboração de uma teoria ontológica da diferença que reconhece o poder como um conceito central na criação de epistemes (Patel, 2013: 122).
} 
Dessa forma, as ciências sociais precisam promover as muitas vozes das tradições sociológicas - infralocais e supranacionais, com todas suas obras culturistas, epistemologias, quadros teóricos, culturas da ciência e línguas de reflexão, sítios de produção de conhecimento e com sua transmissão pelos muitos Suis. Para atingir esse fim, a teoria social precisa afirmar ontologicamente a necessidade de combinar espaços/lugares com uma voz (Patel, 2013: 126). Muitas vezes não é apenas a política econômica da produção de conhecimento que atrapalha essa diversidade, mas os Estados autoritários e as metanarrativas produzidas pelos mesmos.

O desafio, hoje, é a criação de uma infraestrutura intelectual que sirva de interface entre os muitos Suis, dissolvendo as marcas de distinção dentre eles e dentro deles e fazendo com que as suas variadas vozes reconheçam a matriz de poder que organizou essas divisões (Patel, 2013: 126). Connell também defende a diversidade, argumentando que ela implica não somente a aprendizagem sobre o pensamento do Sul, mas a aprendizagem com o pensamento do Sul. Sinha e Alatas enquadram a questão da seguinte forma: podemos pensar com Ibn Khaldun, Marx e Rambhai, e não apenas pensar com Marx e sobre Ibn Khaldun e Rambhai. É impressionante a forma como o intelectual sírio Yasin al-Hafiz realizou sua bricolagem criativa das mais distintas teorias, defendendo um embaçamento historicista da distinção entre liberalismo e socialismo após a derrota de 1967. Eu qualifico essa bricolagem como criativa, para distingui-la da forma como Laroui a vê, como um ecletismo, ou seja, uma adaptação passiva (Laroui, 1967b).

Subsiste a necessidade de uma ciência social menos universalizada, a observar as particularidades de um determinado contexto, e este não é simplesmente uma cultura, é também uma série de cenários sociais, políticos e econômicos com profundidade histórica pré-colonial, colonial, pós-colonial ou autoritária. Nesse sentido, utilizar a cultura muçulmana ou árabe como meio de diferenciação nem sempre ajuda: os países do Golfo são muito mais próximos dos países ocidentais (em sua política econômica, nas características de sociedade de consumo etc.) do que de outros países árabes ou do Oriente Médio.

\section{Referências}

ALATAS, Syed Farid; SINHA, Vineeta. Sociological theory beyond the canon. London: Palgrave Macmillan, 2017.

ARENDT, Hannah. Origins of totalitarianism. New York: Meridian, 1985. 
BARDAWIL, Fadi. The solitary analyst of doxas. An interview with Talal Asad. Comparative Studies of South Asia, Africa and the Middle East, v. 36, n. 1, 2016.

BEIGEL, Fernanda. The politics of academic autonomy in Latin America. Public intellectuals and the sociology of knowledge. Farnham (UK): Ashgate, 2011.

BÉTEILLE, André. The vocation of sociology - a pragmatic view. Global Dialog: International Sociological Association Newsletter, 2013. Disponível em: <http://isa-global-dialogue.net/the-vocation-of-sociology-\%E2\%80\%93-a-pragmatic-view/>.

BHAMBRA, Gurminder K. Connected sociologies. London: Bloomsbury Academic, 2014. BOIS, W. E. B. Du. The soul of black folk. New York: Eucalyptus Press, 2013.

BROWN, Wendy. Politics out of history. Princeton (NJ): Princeton University Press, 2001.

BURAWOY, Michael. Editorial: sociology in an age of reaction. Global Dialog: International Sociological Association Newsletter, 2017.

DABASHI, Hamid. Can non-europeans think? London: Zed Books, 2017.

_. The Arab Spring: the end of postcolonialism. London: Zed Books, 2012.

GERMANA, César. The coloniality of power: a perspective from Peru. Global Dialog: International Sociological Association Newsletter, 2014.

GIROUX, Henry A. Higher education and the politics of hope in the age of authoritarianism: rethinking the pedagogical possibilities of a global democracy. Theomai, n. 15, p. 73-86, 2007.

HANAFI, Sari. Islamization of knowledge and social science: a study of problematics. 2016 (mimeo).

HANAFI, Sari; ARVANITIS, Rigas. Knowledge production in the Arab World: the impossible promise. London (UK): Routledge, 2016.

HARDT, Michael; NEGRI, Antonio. Empire. Cambridge (MA): Harvard University Press, 2001.

HARVEY, David. The new imperialism. Oxford (UK); New York: Oxford University Press, 2005. 
HOFFMANN, Nimi. The knowledge commons, pan-africanism, and epistemic inequality: a study of Codesria. Grahamstown (SA): Rhodes University, 2017. Disponível em: < http://vital.seals.ac.za/vital/access/manager/Repository/vital:27764;jsessionid=BB79D88977E1EC4AA4214D8C85BD708C? exact=sm_publisher\%3A\%22Faculty+of+Humanities\%2C+Institute+of+Social+and+Economic+Research\%22\&fo=sm_date $\% 3 A \% 222018 \% 22>$.

KEEL, Rebecca K. W. Models of participatory budgeting. Democracy in Principle (blog). July 14, 2016. Disponível em: <http://www.democracyinprinciple.com/blog/ models-of-participatory-budgeting/>.

KHATIBI, Abdelkebir. Maghreb pluriel. Paris: Denoël, 1983.

KLUGER, Jeffrey. Why so many people believe conspiracy theories. Time, 2017. Disponível em: <http://time.com/4965093/conspiracy-theories-beliefs/>.

KOHN, Margaret; MCBRIDE, Keally. Political theories of decolonization: postcolonialism and the problem of foundations. Oxford (UK): Oxford University Press, 2011.

LANDER, Edgardo. The discourse of civil society and current decolonisation struggles in South America. Scribd (blog). 2013. Disponível em: <https://www.scribd.com/ document/328096197/the-discourse-of-civil-society-and-current-decolonization-struggles-in-latin-america-pdf>.

— La colonialidad del saber: eurocentrismo y ciencias sociales perspectivas latinoamericanas. Buenos Aires: Clacso, 1993.

LAROUI, Abdullah. L'idéologie arabe contemporaine. Paris: François Maspéro, 1967a.

. The crisis of arab intellectual: traditionalism or historicism? Berkeley (CA): University of California Press, 1967b.

MBEMBE, Achille. African modes of self-writing. Codesria Bulletin, 2000.

MORANA, Mabel; DUSSEL, Enrique; JAUREGUI, Carlos C. Coloniality at large: Latin America and the postcolonial debate. Durham (NC): Duke University Press, 2008.

NASH, Geoffrey; KERR-KOCH, Kathleen; HACKETT, Sarah. Introduction. In: NASH, Geoffrey; KERR-KOCH, Kathleen; HACKETT, Sarah (Eds.). Postcolonialism and islam: theory, literature, culture, society and film. London; New York: Routledge, 2013.

PATEL, Sujata. Towards internationalism: beyond colonial and nationalist sociologies. In: KUHN, Michael; YAZAWA, Shujiro. Theories about and strategies against hegemonic social sciences, p. 119-132. Center for Glocal Studies. Tokyo: Seijo University, 2013. 
PATNAIK, Prabhat. Has imperialism become an obsolete concept? In: BAGCHI, Amiya Kumar; CHATTERJEE, Amita (Eds.).Marxism: with and beyond Marx. New Delhi; London: Routledge, 2011.

PHILLIPS, Christina. The other in modern arabic literature: a critique of postcolonial theory. In: NASH, Geoffrey; KERR-KOCH, Kathleen; HACKETT, Sarah (Eds.). Postcolonialism and islam: theory, literature, culture, society and film. London; New York: Routledge, 2013.

SAID, Edward. Orientalism: Western conceptions of the Orient. London: Penguin, 1978.

SAN JUAN, E. The limits of postcolonial criticism: the discourse of Edward Said. Solidarity (blog). 1998. Disponível em : <https://www.solidarity-us.org/node/1781>.

SCOTT, David. Conscripts of modernity: the tragedy of colonial enlightenment. Durham (NC): Duke University Press, 2004.

USCINSKI, Joseph; PARENT, Joseph. American conspiracy theories. Oxford (UK): Oxford University Press, 2014.

WALLERSTEIN, Immanuel. Eurocentrism and its avatars: the dilemmas of social science. New Left Review, n. 226, Nov.-Dec. 1997. 